Drug Safety - A Shared Responsibility, edited by the International Drug Surveillance Department. Pp. xiii + 126, not illustrated. Churchill Livingstone, Edinburgh, London, Tokyo, New York, Melbourne, 1992. Hardback $£ 9.95$.

This book, written by several members of the International Drug Surveillance Department of Britain's leading pharmaceutical company, provides a basic introduction to adverse event reporting. Most of the contents relate to the UK situation, with occasional reference to the USA and German requirements. The book is aimed at pharmacists, medical students and general practitioners, of whom the first-named are playing an increasingly important role with enquiries, whilst the demands of good clinical practice and speedier international drug development necessitate larger multicentre clinical trials, often with the involvement of community physicians on a wider scale.

The book describes the harvesting of Type $A$ and Type $B$ adverse event reports from clinical trials and from spontaneous reports, the handling of the data accrued within the company and the onward reporting to the regulatory authorities. Other chapters include the various methods of post-marketing surveillance, the structure and function of the Medicines Control Agency, with a subsequent section describing enthusiastically the career opportunities in drug safety within an industrial setting for scientists and physicians. The book concludes with a useful glossary.

It would be impossible to cover every aspect of the work of the Department in a short book and it is, perhaps, unfortunate that the important subjects of toxicology, carcinogenicity and mutagenicity are covered within two pages, in the realization that drugs will be prescribed occasionally and unwittingly to those in early pregnancy. There is neither reference to the handling of such information, nor to the establishment of a pregnancy database for the subsequent dissemination of advice to enquiring physicians, often with far reaching consequences. Surprisingly, there is no mention of the role of matching placebo formulations in Phase II trials, and none of the variable incidence of adverse events generated by such therapy in certain indications and the obvious importance of relating such levels to those from comparative treatment with active compound. The important subject of code-breaking in clinical trials, when and by whom, and appropriate dissemination of the information to ethics committees, as well as to regulatory authorities and coinvestigators where required, is overlooked.

Given this impossibility of covering all the issues under possible consideration, this eminently readable book should stimulate and enhance the shared and crucial responsibility for reporting adverse events and for monitoring drug safety.

G. Macdonald

$R \& D$ Department, Bayer plc, Newbury.

Berks RG13 IJA.

Post Viral Fatigue Syndrome, edited by Rachel Jenkins and James Mowbray. Pp. xxiii +462 . John Wiley \&
Sons, Chichester, New York, Toronto, Singapore, 1991.ج Hardback $£ 60$.

Amid increasing medical and public concern about condi- $-\stackrel{\overrightarrow{\vec{F}}}{\overrightarrow{\underline{m}}}$ tions which are characterized by persistent, excessive and $\stackrel{?}{?}$ debilitating fatigue, this book is a welcome addition. However, to prejudge the aetiology of the condition in the title, 'post-viral fatigue syndrome', rather than that of $\overline{\bar{c}}$. 'chronic fatigue syndrome' is perplexing. Furthermore $\mathbb{\Phi}$ the editors have allowed the many authors to use disparate nomenclature in the chapter titles, which include ${ }^{\text {क }}$ myalgic encephalomyelitis, chronic fatigue syndrome and $\vec{\circ}$ even chronic post-viral fatigue syndrome.

Much repetition occurs throughout this book, but cer- $\vec{\omega}$ tain chapters commendably discuss this complex group of conditions: in particular I enjoyed the chapter entitledo 'Interpreting the role of depression in chronic fatigue 3 . syndrome'. In contrast, the section on 'Laboratory abnormalities in chronic fatigue syndrome' however becomes little more than a list of conflicting data. The $\stackrel{+}{\vec{\prime}}$ review of chronic viral infections of the brain discusses classical viral and prion-related disorders, however, no $\vec{A}$ attempt is made to relate the pathological processeso involved in these diseases with those in chronic fatigue syndrome.

The debate concerning the aetiology of this illness will continue. The concept that diminished immunity, subsequent upon stress, could lead to a predisposition of $\vec{a} \overrightarrow{0}$ variety of infective conditions is well presented and masy help to draw together those individuals that have conce tual difficulties in balancing the results of viral studis with prominent psychological factors.

This book is well worth perusing but the reader must try to maintain an objective viewpoint as he or she pro- $\%$ gresses through this collection of articles.

\section{R.J. Powell $\stackrel{\overrightarrow{\vec{c}}}{3}$ \\ Department of Immunology, University Hospital, Queen's Medical Centre, Nottingham NG7 2UH.}

Granulomatous Infections, edited by D.M. Williams. $\frac{\dot{\sigma}}{\square}$ Pp. 187, illustrated. Churchill Livingstone, Edinburgh, London, New York, Tokyo, Melbourne, 1991. Hardback $£ 22.50$.

Churchill Livingstone have embarked on a new series of monographs dealing with contemporary management in $\frac{7}{0}$ internal medicine. Forthcoming issues will include acute myocardial infarctions, nephrology, obstructive lung $N$ disease, haematological malignancy and the bowel. They emerge from the University of Texas, San Antonio, so 0 they will provide an American slant on management. This $\mathrm{N}_{\mathrm{U}}$ issue is on granulomatous infections, comprising six chapters on antifungal therapy, coccidioidomycosis, histoplasmosis, meningitis, pulmonary tuberculosis and mycobacterial disease in human immunodeficiency virus $\stackrel{\mathcal{Q}}{\rightarrow}$ infection.

You may say that this is of limited appeal for some of $\frac{T}{0}$ these infections are rare in Europe; histoplasmosis is more $\underset{\mathbb{D}}{\stackrel{\mathrm{D}}{*}}$ at home in Ohio and coccidioidomycosis in California. $\stackrel{?}{\stackrel{P}{Q}}$ However, granulomatous disease is common worldwide $\stackrel{\mathbb{Q}}{\varrho}$ 